\title{
O DIREITO COMUNITÁRIO, A UNIÃO EUROPEIA E A IMPORTÂNCIA DAS AÇÕES AFIRMATIVAS ANTE A GLOBALIZAÇÃO.
}

\author{
COMMUNITY LAW, THE EUROPEAN UNION AND THE IMPORTANCE OF \\ AFFIRMATIVE ACTIONS BEFORE GLOBALIZATION.
}

\author{
KIWONGUI BIZAWU ${ }^{1}$ \\ VIVIANE CÔELHO DE SÉLLOS KNOERR ${ }^{2}$ \\ VIRGINIA MARIA CURY JOSÉ ${ }^{3}$
}

\section{RESUMO}

O presente artigo tem como objetivo principal o estudo doutrinário sobre a União Europeia, dentro do Direito Comunitário, e a importância das ações afirmativas. Para tanto será traçada uma breve evolução histórica da União Europeia, bem como breves considerações sobre o Direito Comunitário, bem como a ligação com ações afirmativas. Ademais, os Tratados que criaram a União Europeia, formam o objeto do Direito Comunitário. O Direito Comunitário é um Direito de Integração, aperfeiçoado, evoluído. Após a Segunda Guerra Mundial, houve a necessidade de unir os Países da Europa (União Europeia), devido às crises financeiras e às

1 Possui graduação em Curso de Direito pela Faculdade de Ciências Jurídicas e Sociais Vianna Júnior (2000), graduação em Institut de Philosophie Saint Augustin - Institut de Philosophie Saint Augustin (1986), graduação em Teologia - Institut de Théologie Eugène de Mazenod (1990), mestrado em Direito pela Pontifícia Universidade Católica de Minas Gerais (2006) e doutorado em Pos-graduacao em Direito pela Pontifícia Universidade Católica de Minas Gerais (2011). Pós-Doutorado na Universidade de Coimbra - Portugal. Ius Gentium Conimbrigae/Centro de Direito, UCPT /(IGC/CDH), Portugal (2017-2018), Membro do Conselho Curador da Fundação Movimento do Direito e Cidadania (FMDC), Professor do Direito Internacional, Pro-Reitor do PPGD em Direito Ambiental e Desenvolvimento Sustentável da Escola Superior Dom Helder Câmara, professor visitante de direito civil II e III e da "Législation en Matière Economique" da UNIVERSITÉ DU KWANGO (UNIK), sacerdote auxiliar - Mitra Arquidiocesana de Belo Horizonte, Congregação do Verbo Divino, professor titular da Escola Superior Dom Helder Câmara e Coordenador do Centro de Estudos afro-brasileiros (AFRODOM) da Escola Superior Dom Helder Câmara com apoio da FAPEMIG. Líder do Grupo de Pesquisa "Direito Animal, Economia, Cultura, Sustentabilité e Proteção Internacional". Membro do Grupo de Pesquisa Estratégica Panamazônia. Tem experiência na área de Direito, com ênfase em DIREITO AMBIENTAL E DESENVOLVIMENTO SUSTENTÁVEL, atuando principalmente nos seguintes temas: direitos humanos, meio ambiente e desenvolvimento sustentável, direito internacional, Direito Internacional Ambiental, Direito internacional Humanitário, sustentabilidade e Direito Animal.

\footnotetext{
${ }^{2}$ Realizou estágio Pós-Doutoral na Universidade de Coimbra. Doutora em Direito do Estado pela Pontifícia Universidade Católica de São Paulo. Mestre em Direito das Relações Sociais pela Pontifícia Universidade Católica de São Paulo. Graduada em Direito pela Universidade Federal do Espírito Santo É advogada. Professora e Coordenadora do Programa de Mestrado e Doutorado em Direito Empresarial e Cidadania do Centro Universitário Curitiba / UNICURITIBA. Tem experiência em: Responsabilidade Social da Empresa. Dignidade da Pessoa Humana. Cidadania. Ética. Interpretação e Aplicação da Constituição. Tutela de Direitos Difusos e Coletivos. Advogada.

${ }^{3}$ Graduada em Direito pela PUC-PR. Pós-Graduada em Direito pela EMATRA. Pós-Graduada em Direito pela FEMPAR. Pós-Graduada em Direito pela EMAP. Mestranda em Direito Empresarial e Cidadania no Centro Universitário Curitiba- UNICURITIBA. Curitiba- PR. E-mail: virmaria@terra.com.br
} 
atrocidades de Adolf Hitler que desrespeitou, em muito, os Direitos Humanos. No começo da década de cinquenta, iniciaram-se os Tratados para que a União Europeia existisse e acabasse com o abalo à paz mundial. A metodologia utilizada nesta pesquisa foi a do método dedutivo; quanto aos meios a pesquisa foi a bibliográfica, com uso da doutrina e legislação.

Palavras-chave: União Europeia; Ações Afirmativas; Globalização; Direito Comunitário.

\begin{abstract}
This article has as main objective the doctrinal study on the European Union, its importance, creation and composition. For this, it will be made a brief historical development of the European Union, as well as considerations on the Community Law, as it is its main representative. In addition of the Treaties that created the European Union, form the object of the Community Law. Community law is a right of integration, perfected, evolved. After World War II, there was a need to unite the countries of Europe (European Union), due to the financial crises and the atrocities of Adolf Hitler that disrespected human rights very much. In the early 1950s, the Treaties were started so that the European Union would exist and end the shaking of world peace. The methodology used in this research was that of the deductive method; as to the means the research was the bibliographical one, with use of the doctrine and legislation.
\end{abstract}

Keywords: European Union, Affirmative Action, Globalization, Community Law.

\title{
1 INTRODUÇÃO
}

A partir da Segunda Guerra Mundial, que encerrou em 1945, ocorreu a bipolarização do planeta em dois blocos: o bloco americano, que tinha um viés capitalista e o bloco da União Europeia, que tinha um viés comunista.

A Sociedade Internacional ficou globalizada e esta globalização tomou força após a queda do muro de Berlim e também após a queda da potência soviética. O modelo norteamericano ganhou o planeta e beneficiou alguns setores da sociedade como as empresas privadas que, com a globalização, começaram a tirar o poder dos Estados. Nesse diapasão os Estados sofreram a perda do poder devido ao setor privado e à Segunda Guerra Mundial.

Por tais razões, os Estados se reuniram a fim de vencer os problemas mundiais, as crises financeiras, a pobreza, bem como terem mais recursos.

Então, o Direito Comunitário começa a ganhar força a partir da Segunda Guerra Mundial, quando os países se uniram para tentarem vencer as adversidades do planeta. O Direito de Integração, o Direito Comunitário, os Blocos Econômicos (União Europeia; Mercosul...) surgiram da necessidade de os Estados sobreviverem. 
O Direito de Integração e o Direito Comunitário, para crescerem após a Segunda Guerra Mundial, precisaram "mudar suas cabeças", abandonando e reformulando o conceito de soberania. Aquela soberania clássica precisava ser abandonada para que os blocos econômicos existissem. Logo, a soberania clássica foi substituída por uma soberania compartilhada.

A soberania compartilhada é aquela em que os Estados se unem e delegam parte de sua competência a um órgão superior, por não conseguirem solucionar, sozinhos, seus problemas. Precisam se unir, abrindo mão de parte de sua soberania.

A União Europeia tem sua soberania compartilhada, ou seja, os Estados abrem mão de parte de sua competência para que um órgão superior decida por eles, porque não podem solucionar, sozinhos, todas suas problemáticas.

A soberania compartilhada também é conhecida como supranacionalidade (existe um órgão superior aos Estados). É o que existe na União Europeia, onde o sistema é da supranacionalidade.

Já o Mercosul é um bloco econômico que não tem supranacionalidade. É um bloco atrasado em que seu processo de integração é lento e não chegou ao nível de desenvolvimento da União Europeia. No Mercosul, o sistema é da intergovernabilidade (os governos decidem mediante consenso). Esse sistema não é muito eficiente.

Antigamente, os Estados baseavam-se no princípio da autotutela, que era a soberania clássica, levando em consideração seus próprios interesses. Mas após a Segunda Guerra Mundial, devido às crises, o princípio da autotutela começou a dar lugar ao princípio da solidariedade e ao princípio da segurança coletiva. O individualismo foi trocado pelo coletivismo (interesse da coletividade) e os Estados começaram a formar os blocos econômicos.

Após a Segunda Guerra Mundial a sociedade internacional e globalizada começou a ser conhecida como sociedade de risco, ou seja, aquela sociedade em que todos estavam vulneráveis a algum fato. Esta sociedade de risco é a sociedade globalizada e dentro dela a cooperação entre os povos deve observar ações afirmativas de inclusão social.

Os blocos econômicos são imprescindíveis para a existência dos Estados, pois assim tais Estados têm tratamentos privilegiados não ficando isolados. Isso porque o bloco econômico é um conjunto de Países, de Estados, que se unem e criam um ambiente ideal para o comércio internacional. Criam tratamentos privilegiados em relação a seus membros, ao reduzirem tarifas, impostos e unificarem tarifas externas comuns.

Ademais, os blocos econômicos como o Mercosul; União Europeia; Alca e Nafta, além de outros, têm personalidade jurídica própria. Mas os blocos econômicos não têm o mesmo nível de integração, inclusive o nível de integração da Comunidade Europeia é maior do que o 
do Mercosul. A União Europeia para chegar a ser esta Comunidade Europeia, passou por diferentes fases.

Neste diapasão, este artigo possui como objetivo, analisar a União Europeia, como um todo, passando pelas noções gerais de sua criação, bem como pelos principais documentos que fizeram parte de sua evolução histórica, como o Tratado de Lisboa de 2007, além de identificar os órgãos que a compõe e quais as suas funções e também abordar as ações afirmativas que é um dos direitos basilares da Constituição Federal de 1988, corrigindo desigualdades mesmo na globalização.

Como, hodiernamente, a União Europeia é a principal representante do Direito Comunitário, em um primeiro momento, serão feitas breves considerações sobre o Direito Comunitário e na segunda parte será feito um panorama sobre a União Europeia, através de pesquisas bibliográficas, dentro de um método dedutivo.

\section{BREVES CONSIDERAÇÕES SOBRE O DIREITO COMUNITÁRIO}

\subsection{CONCEITO}

O Direito Comunitário pode ser entendido como desdobramento do Direito Internacional, contudo, apresentando uma percepção público-privado. Não se confunde com o Direito da Integração, que objetiva o envolvimento comercial e econômico. Hoje, é o patamar do Mercosul.

O Direito Comunitário tem como balizas a aplicabilidade imediata, efeito direto e prevalência. Aqui, os Estados abrem mão de parte de sua soberania, aceitando a decisão dos tratados, automaticamente.

Logo, o Direito Comunitário não se confunde com o Direito da Integração, embora afins em alguns aspectos não são disciplinas idênticas.

O Direito Comunitário, por sua vez, pode até ser considerado uma forma de Direito de Integração aperfeiçoado, evoluído.

O Direito da Integração tem como objeto principal a integração de natureza eminentemente comercial e econômica, visando ao incentivo do comércio internacional de uma região.

Diego Pereira Machado (2012, p.372), esclarece que: 
O principal representante do Direito Comunitário, seu criador, reconheça-se, é o bloco União Europeia, o mais integrado e desenvolvido, modelo para os demais, a despeito das crises de ordem financeira e econômica que assolam alguns dos membros. $\mathrm{O}$ modelo comunitário europeu já começou a influenciar outros blocos, um importante exemplo é o da Comunidade Andina de Nações a qual optou por molde semelhante ao europeu em seu documento constitutivo, ainda que muito precise ser feito para que possa ser considerada comunidade inteiramente regulada pelo Direito Comunitário.

O Direito Comunitário é uma disciplina autônoma, não inserida dentro do Direito Internacional e, muito menos, dentro dos Direitos internos, possuindo as seguintes características:

a) os Estados, unidos por uma comunidade, estão submetidos a instituições de caráter supranacional;

b) as normas comunitárias possuem aplicação direta em relação aos ordenamentos nacionais;

c) há um órgão central com função executiva e de natureza supranacional.

d) possui sistema jurisdicional bem definido, que é a base do sistema de solução de controvérsias;

e) há Tribunal de Justiça, permanente, que zelará pela aplicação e respeito ao Direito Comunitário;

f) no Direito Comunitário não são só os aspectos econômicos e comerciais que são levados em consideração, pois outros desafios de natureza social e política também são objetos das normas;

g) parte do exercício da soberania dos Estados é delegada a órgãos com poder supracional;

h) os Estados membros ainda são soberanos, embora esta soberania esteja limitada pela supranacionalidade.

Diego Pereira Machado (2012, p.373) conclui, ainda que:

\begin{abstract}
A diferença essencial entre o ordenamento comunitário e o internacional consiste em que este não se impõe à ordem jurídica dos Estados, não existindo, como se sabe, uma ascendência jurídica de tribunal internacional sobre os cortes nacionais. Já em relação ao Direito Comunitário (supranacional), ocorre, fruto de sua composição sui generis, uma subordinação das ordens jurídicas internas ao Tribunal de Justiça da União Europeia.
\end{abstract}

Ademais, o Direito Comunitário tem algumas peculiaridades básicas como a aplicabilidade imediata (suas normas adquirem imediatamente o status de direito positivo no ordenamento jurídico de cada Estado-membro), o efeito direto (cria direitos e obrigações por 
si mesmo) e a prevalência (a norma comunitária tem primazia sobre a norma interna dos países integrantes da Comunidade).

Pelas razões apresentadas, não se deve confundir o Direito Comunitário com o Direito Internacional.

O Direito Comunitário é uma gradação do Direito Internacional e vai além de um Direito Público ou de um Direito Privado.

No entanto, quando se fala em Direito Internacional Público aborda-se, com certeza, a questão dos tratados que são incorporados. Ao serem incorporados passam por toda uma dinâmica interna, pelo Executivo e Legislativo.

Quanto ao conceito de Direito Internacional Público, Valério de Oliveira Mazzuoli (2007, p.43) adverte:

\footnotetext{
Sinteticamente, o Direito Internacional Público pode ser definido como a disciplina jurídica da sociedade internacional. Em uma definição mais abrangente (e mais técnica), o Direito Internacional Público pode ser conceituado como o conjunto de princípios e regras jurídicas (costumeiras e convencionais) que disciplinam e regem a atuação e a conduta da sociedade internacional (formada pelos Estados, pelas organizações internacionais intergovernamentais e também pelos indivíduos), visando alcançar as metas comuns da humanidade e, em última análise, a paz, a segurança e a estabilidade das relações internacionais.
}

O Direito Comunitário tem uma outra percepção, pois não há a ideia de recepção dos tratados. Isto porque o Direito Comunitário entende que há um avanço sobre as questões de soberania, ou seja, os Países que compõem o Direito Comunitário, deixam de ter parte da soberania para aceitar o Direito Comunitário. Ao invés de serem discutidos os tratados internacionais, dentro do Legislativo, serão aceitos simplesmente. Todos os Países integrantes do Direito Comunitário vão incorporar os tratados sem a necessidade de recepção pelo ordenamento interno.

Enquanto no Direito Internacional Público tradicional há toda uma discussão sobre recepção de tratados, no Direito Comunitário, quando votado por todos, no Parlamento Europeu, por exemplo, já não há mais o que se discutir sobre recepção. Isso pode levar a discussões sobre o fato do País poder ou não, abrir mão de sua soberania para aceitar tratados.

\subsection{FONTES DO DIREITO COMUNITÁRIO}

Convém esclarecer que no Direito Internacional, pelo art. 38 do Estatuto da Corte Internacional da Justiça (CIJ), há fontes formais como os tratados, princípios gerais e costumes. 
Além delas, o Direito Internacional Público ainda carrega as decisões das Organizações Internacionais e atos unilaterais. Estas cinco fontes têm importância para o Direito Internacional.

No entanto, no Direito Comunitário tem-se a ideia de fontes originárias e fontes derivadas.

As fontes originárias ou primárias são todas as normas respeitantes aos tratados, inclusive as suas alterações, protocolos e anexos. São os tratados que criaram a União Europeia. Ex: Tratado de Roma; Tratado de Maastrich, Tratado de Nice.

As fontes derivadas dividem-se em regulamentos, diretivas, decisões, pareceres e recomendações.

a) Os regulamentos são normas gerais, impessoais, abstratas e com efeitos erga omnes. São normas obrigatórias e diretamente aplicáveis a todos os Estados- Membros. São atos legislativos por excelência e têm caráter geral.

b) As diretivas são normas específicas destinadas a um ou mais Estados. Precisam ser aprovadas pelos Estados para terem força dentro deles. Então as diretivas precisam da internalização, ou seja, precisam ser recepcionadas. As diretivas vinculam os Estados-membros destinatários quanto ao resultado a alcançar, deixando-lhes a competência quanto à forma e aos meios. Tem que ser obrigatoriamente transportadas para o Direito interno de cada Estado. É a questão de abrir mão da soberania estatal em prol das questões diretivas.

c) As decisões obrigatórias são obrigatórias somente aos seus destinatários. Os destinatários são os particulares, os indivíduos, as empresas e os Estados- membros.

d) As recomendações e pareceres não são obrigatórios, não têm força vinculante. São destinados às Empresas, aos Estados- membros e às Instituições da União Europeia. As recomendações e os pareceres não sendo atos vinculativos não carecem de publicação.

As normas de Direito Comunitário, levando em conta a supranacionalidade, são aplicadas de forma direta pelos Estados- membros. Não precisam de internalização. A aplicação das normas, na União Europeia, é direta.

No entanto, no Mercosul é diferente porque há a intergovernabilidade, consenso. No Mercosul não tem supranacionalidade, não tem órgão superior. As decisões, embora obrigatórias, precisam ser internalizadas, recepcionadas. Então, no Mercosul as normas não têm aplicação direta; elas precisam de internalização.

Em suma, quando se fala em Direito Comunitário, a melhor exemplificação é a União Europeia a qual será tratada, na sequência, neste artigo científico. 


\section{NOÇÕES GERAIS SOBRE A CRIAÇÃO DA UNIÃO EUROPEIA}

A União Europeia é uma Comunidade Europeia, é uma organização de Países democráticos que delegam parte de sua soberania a instituições comuns aos Estados- membros, objetivando obter prosperidade, unindo interesses econômicos, políticos e sociais.

A necessidade de unir os Países da Europa surgiu após a Segunda Guerra Mundial, devido às crises financeiras, às atrocidades desta guerra e à insanidade de Adolf Hitler que foi de encontro aos direitos humanos, causando feridas difíceis ou impossíveis de cicatrizar, visto que feriram gerações. Então a Europa se uniu para acabar com o abalo à paz mundial.

No começo da década de cinquenta começaram a surgir os tratados para a União Europeia existir. A França bem como a Alemanha, tiveram muita participação para a constituição da União Europeia.

Na União Europeia há a soberania compartilhada que é a própria supranacionalidade (órgãos superiores ditam regras e fazem as normas do Direito Comunitário serem cumpridas).

A União Europeia sofreu modificações em 2007, com o Tratado de Lisboa, que em 01/12/2009 entrou em vigor, modificando a estrutura e eficiência da União Europeia (estabeleceu novas atribuições; reforçou as instituições; criou o cargo de Ministro das Relações Exteriores, para uma pessoa representar no exterior a União Europeia, tendo também um Presidente).

A União Europeia tem personalidade jurídica única por causa do Tratado de Lisboa, assinado em 2007, mas que só entrou em vigor em 01/12/2009. Esse Tratado além de atualizar, reformar, tornar mais eficiente a União Europeia, lhe deu personalidade jurídica única: passou a ser uma só, única.

Não se deve confundir a União Europeia com a própria ideia de Europa, pois nem todo País Europeu compõe a União Europeia.

Krieger delineou alguns princípios norteadores das relações internacionais concernentes à União Europeia, que são (KRIEGER, 2006, p.75):
a) a união dos homens;
b) a primazia do Direito sobre a força;
c) a igualdade de direitos;
d) a delegação de soberania;
e) a força das instituições.

Nesse diapasão, Diego Pereira Machado (2012, p.411) explica que: 
Conforme art.222 do Tratado sobre Funcionamento da UE, a União e os seus Estadosmembros atuarão em conjunto, num espírito de solidariedade, caso um outro membro seja alvo de ataque terrorista ou vítima de catástrofe natural ou de origem humana. A União, nesses casos, mobilizará todos os instrumentos ao seu dispor, inclusive os recursos militares, para prevenir ameaças terroristas, proteger as instituições democráticas e a população civil e prestar assistência a Estado coirmão, na hipótese de ataque terrorista.

Então, esta obrigação de ser solidário, de estar integrado, é o cerne de todo o processo de integração. Concretizar tal obrigação é fadar ao sucesso qualquer proposta de bloco regional.

Além do mencionado princípio da solidariedade, a União Europeia também é regida pelos princípios da igualdade, do equilíbrio institucional, da uniformidade, da subsidiariedade e da proporcionalidade, devendo, como potência que é, promover também as ações afirmativas (equilibrar balanças desiquilibradas).

Quanto à solidariedade, temos na globalização a ideia de obter recursos em benefícios de pessoas pertencentes a grupos discriminados por razões sociais, religiosas, de gênero ou de casta. Um País ajudando o outro nessa luta.

Para tal desiderato, a União Europeia é sujeito de Direito Internacional, podendo celebrar acordos e tratados. A União Europeia é um bloco econômico forte, regulado pelo Direito Comunitário. É uma Comunidade. É chamada de União Europeia ou Comunidade Europeia.

\section{PRINCIPAIS DOCUMENTOS QUE FIZERAM PARTE DA EVOLUÇÃO HISTÓRICA DA UNIÃO EUROPEIA}

Quanto à formação dos blocos, as ideias para se criarem blocos econômicos, na União Europeia, começaram a surgir no começo da década de cinquenta.

Em 1951, surgiu a Comunidade Europeia do Carvão e do Aço (CECA), por meio do Tratado de Paris. França e Alemanha acordaram sobre o controle comum nos domínios do carvão e do aço. Foi o primeiro projeto de união entre os países europeus após anos de conflitos.

Em 1957, foi criada a Comunidade Econômica Europeia (CEE), pelo Tratado de Roma. Juntamente com a Comunidade Econômica Europeia, foi criada a Comunidade Europeia de Energia Atômica (CEEA). A partir da criação da CEE, novos países começaram a integrar o bloco.

Em 1968, começou a ser adotada a livre circulação de pessoas, por meio do Regulamento 1.612 de 1968. Encerra-se a fase transitória de mercado comum europeu. 
Em 1985, o Acordo de Schengen, completado por uma Convenção de Aplicação, facilitou o exercício da liberdade de circulação dos cidadãos europeus, abolindo os controles nas fronteiras internas da União e reforçando o controle nas fronteiras externas para a entrada de imigrantes, unificando a importante política para a concessão de vistos.

Em 1986, ocorreu a primeira revisão do Tratado de Roma, por meio do Ato Único Europeu, assinado em Luxemburgo, com entrada em vigor no ano de 1987. Essa fonte do Direito Comunitário caracterizou a terceira fase do processo de integração, prevendo as devidas adaptações para completar o mercado interno, consolidando a abolição das fronteiras internas por meio da implementação efetiva das cinco liberdades: de bens, de trabalhadores, de serviços, de capitais e de concorrência.

Em 1992, foi assinado o Tratado da União Europeia ou Tratado de Maastricht que entrou em vigor em 1993. Ele criou a União Europeia nos moldes hoje conhecidos, uma união econômica e monetária. O presente documento tem objetivos de natureza econômica, busca a união social e política, a instituição de uma cidadania e o estabelecimento de uma política comum.

Em 1997, foi celebrado o Tratado de Amsterdã. O Tratado de Amsterdã revisou, atualizou e modificou o Tratado de Roma, definindo as Instituições que hoje compõem a União Europeia.

Em 1999, começou a vigorar a moeda comum, o euro (moeda única da Europa). O euro começou a circular em 01/01/2002 e foi adotado por metade dos Países da União Europeia. Junto com o euro, foi criado o Banco Central da União Europeia, com personalidade jurídica própria e sede em Frankfurt na Alemanha.

Em 2001, foi celebrado o Tratado de Nice que adaptou os tratados de Roma e de Maastricht, trazendo mudanças à Comunidade Europeia.

Em 2005, a União Europeia tentou uma Constituição para o bloco (Tratado Constitucional), almejando atingir a última e quinta fase do processo de integração, a união política. No entanto, o projeto não vingou, pois muitos países não ratificaram o tratado, como, por exemplo, a França e a Holanda.

Em 2007, em substituição ao fracasso do projeto de Constituição, a União Europeia celebrou o Tratado de Lisboa, o qual reproduziu, quase que em sua integralidade, o texto daquele documento. O Tratado de Lisboa entrou em vigor em 01/12/2009.

\subsection{TRATADO DE LISBOA DE 2007}


O Tratado de Lisboa é de importância ímpar porque almejou aperfeiçoar a integração entre os países europeus e teve por fim dar mais eficiência às suas instituições, adaptando-as aos atuais membros e aos que ainda virão.

Conforme as lições de Diego Pereira Machado (2012, p.413):

O documento de Lisboa é um tratado reformador, modificador dos tratados constitutivos da União Europeia, para ser mais exato. Os documentos modificados são: o Tratado Institutivo da Comunidade Europeia de 1957; o Tratado Institutivo da Comunidade Europeia de Energia Atômica de1956; e o Tratado da União Europeia ou de Maastricht de 1992.

Na mesma linha dos Tratados de Nice e de Amsterdã o, de Lisboa também alterou outros tratados. A peculiaridade é que os textos reformados passam a ter uma nova redação, a princípio, mas coadunam com os anseios dos países-membros da União Europeia, a qual passa a ter estrutura fortificada para enfrentar os desafios contemporâneos.

A União Europeia passou a ser entidade única, dotada de personalidade jurídica, ainda com capacidade para celebrar acordos ou participar de outras organizações internacionais. Então não se falou mais em Comunidades Europeias, mas sim, unicamente, em União Europeia. A partir de dezembro de 2009: só União Europeia!

As instituições atuais da União Europeia foram mantidas, o que ocorreu foi a implementação de reformas que almejaram dar mais eficiência ao seu funcionamento, como por exemplo:

a) a União Europeia teve um Presidente que foi o Primeiro Ministro da Bélgica, conservador e de direita.

b) teve, também, um Ministro das Relações Exteriores, quer era uma mulher esquerdista e radical.

c) o Parlamento Europeu ganhou mais força, juntamente com os parlamentares nacionais, com novos poderes no que se referiu à legislação a ao orçamento da União, bem como aos acordos internacionais.

d) o Tratado de Lisboa inovou e reconheceu expressamente o direito de saída ou retirada do bloco.

e) quanto ao processo legislativo europeu ordinário: o principal processo de decisão da União passou a se chamar processo legislativo ordinário, no qual participaram o Conselho e o Parlamento Europeu (co-decisão). Sistema aplicável na maioria das matérias, reduzindo-se, dessa forma, as votações por unanimidade.

f) a União Europeia ganhou uma personalidade jurídica única. 


\section{5 ÓRGÃOS QUE COMPÕEM A UNIÃO EUROPEIA E SUAS FUNÇÕES}

O art. 13 do Tratado da União Europeia preceitua que ela dispõe de um quadro institucional que visa a promover os seus valores, prosseguir os seus objetivos, servir os seus interesses, os dos seus cidadãos e os dos Estados-membros, bem como assegurar a coerência, a eficácia e a continuidade das suas políticas e das suas ações. As instituições da União Europeia são:
a) o Parlamento Europeu;
b) o Conselho Europeu;
c) o Conselho;
d) a Comissão Europeia;
e) o Tribunal de Justiça da União Europeia;
f) o Banco Central Europeu;
g) o Tribunal de Contas da União Europeia.

O Direito Comunitário foi se desenvolvendo para chegar à noção que temos hoje no art.13 do Tratado da União Europeia, isto é, a existência de órgãos próprios. Nessa esteira, não se deve confundir União Europeia com a ideia de Europa. Nem todo País europeu compõe a União Europeia. Hoje são vinte e oito membros, mas a União Europeia, fazendo parte de um tratado, abre mão de parte de sua soberania para ampliação sobre acordos de comércio, economia e pessoas, tendo uma moeda única desenvolvida.

Então, para que a União Europeia pudesse organizar suas atividades foram criados vários órgãos que fazem parte de sua composição.

\subsection{PARLAMENTO EUROPEU}

O Parlamento tem sua sede em Estrasburgo, na França, mas seu Secretariado geral se encontra em Luxemburgo e as suas comissões se reúnem em Bruxelas.

Trata-se de instituição supranacional, de caráter essencialmente político, que exerce, juntamente com o Conselho, a função legislativa e a função orçamentária.

A definição do orçamento da União e a produção legislativa não são exercidas em sua plenitude, pois o Parlamento, só em determinados casos, participa no exercício do poder normativo e tem uma intervenção limitada na aprovação do orçamento comunitário. Nesta 
particularidade se diferencia do perfil de muitos Parlamentos nacionais, tendo em vista que as atividades legislativas e orçamentárias são, normalmente, atribuídas sem restrições aos respectivos Legislativos.

O Parlamento exerce funções de controle político ou supervisão e de consulta. Dentre suas várias atribuições, elencadas pelos tratados comunitários, cabe-lhe eleger o presidente da Comissão Europeia. Além da função legislativa, o Parlamento tem a função de discussão e aprovação do orçamento da União Europeia, bem como a função consultiva, de supervisão e fiscalização.

A composição do Parlamento é a mais democrática possível, em se tratando de instituição que melhor representa a vontade popular em nível comunitário, haja vista ser composto por representantes dos cidadãos europeus, eleitos por sufrágio universal, direto, livre e secreto, para exercerem mandato de cinco anos, gozando de imunidade parlamentar. É a única instituição que possui o sistema de eleições diretas.

\subsection{CONSELHO EUROPEU}

O Conselho Europeu é o órgão supremo da União Europeia, constituído pelos Chefes de Estado e os Chefes de Governo, os quais são auxiliados pelos Ministros das Relações Exteriores, neste Conselho Europeu.

O Conselho Europeu, como é órgão supremo, funciona como uma última instância recursal. O Conselho Europeu é uma instituição tida como o órgão supremo da União Europeia, sendo constituída pela reunião dos Chefes de Governo ou Chefes de Estado dos membros da Comunidade, assistidos pelos Ministros das Relações Exteriores.

Ele tem por missão dar os impulsos necessários ao desenvolvimento da união, definindo suas orientações e prioridades políticas gerais. Não exerce função legislativa e se reúne duas vezes por semestre, por convocação de seu Presidente, pronunciando-se, em regra, por consenso. Quando a situação exigir, o Presidente poderá convocar uma reunião extraordinária.

\subsection{CONSELHO}

O Conselho ou Conselho da União Europeia, não pode ser confundido com o Conselho Europeu e nem, com o Conselho da Europa. Somente o Conselho Europeu e o Conselho da União Europeia (Conselho), são instituições da União Europeia. 
O Conselho é o principal órgão legislativo e executivo da União Europeia. Exerce, juntamente com o Parlamento Europeu, a função legislativa e a função orçamentária. Cabe a ele definir as políticas da União Europeia e desenvolver atividade de coordenação do bloco, deliberando, em regra, por maioria qualificada. É composto por um representante de cada Estado-membro a nível ministerial, com poderes para vincular o governo do respectivo Estado e exercer o direito de voto.

\subsection{COMISSÃO EUROPEIA}

A Comissão Europeia é uma instituição politicamente independente que representa e defende os interesses da União Europeia e os programas de ação, com responsabilidade de aplicar as decisões do Parlamento e do Conselho.

Tal Comissão é composta por comissários, que representam os Estados membros da União Europeia, com mandato de cinco anos.

A Comissão tem como função promover o interesse geral da união, competindo-lhe velar pela aplicação dos tratados, bem como pelas medidas adotadas nas demais instituições. É uma espécie de governo da União Europeia que executa o orçamento e gere os programas definidos pelo bloco. Exerce funções de coordenação, de execução e de gestão, além de tomar a iniciativa da programação anual e plurianual da União com vistas à obtenção de acordos interinstitucionais.

A Comissão assegura a representação externa da União, excetuando-se a política externa e de segurança comum e dos demais casos previstos nos tratados.

Semelhante ao papel do Parlamento Europeu, a Comissão exerce atividade consultiva, pois pode formular recomendações ou pareceres sobre matéria objeto dos tratados.

A Comissão Europeia exerce suas atividades com total independência, não podendo seus membros solicitar e, muito menos, aceitar instruções de nenhum governo, instituição, órgão ou organismo. Seus integrantes devem abster-se de toda e qualquer ação que seja incompatível com os seus deveres ou com o exercício das funções.

Por fim, é importante ressaltar que a Comissão é a "Guardiã dos Tratados". Nesse sentido Joana Stelzer (2000, p.53), esclarece que:

O principal objetivo da Comissão está em garantir o respeito absoluto de todas as normas das Comunidades e dos princípios que lhe são concernentes. Funciona, portanto, como verdadeira guardiã da ordem jurídica comunitária. 
Então, é como se fosse um "governo" da União Europeia, pois a impulsiona e zela pelo cumprimento dos tratados comunitários.

\subsection{TRIBUNAL DE JUSTIÇA DA UNIÃO EUROPEIA}

O Tribunal de Justiça da União Europeia é composto por um juiz de cada Estadomembro, os quais são escolhidos de comum acordo pelos governos dos Estados e tem o poder de resolver os conflitos legais entre os Estados membros, instituições da União Europeia, empresas e particulares. Mas, não é instância recursal para os tribunais nacionais dos Estados.

Este Tribunal detém a competência jurisdicional para as questões de Direito Comunitário, cabendo a ele garantir o respeito ao direito na interpretação e aplicação dos tratados europeus, sendo o órgão jurisdicional supranacional do sistema judicial de solução de controvérsias da União Europeia.

A competência do Tribunal de Justiça da União Europeia é ampla e algumas delas são: fiscalizar a legalidade dos atos adotados em conjunto pelo Parlamento Europeu e pelo Conselho, dos atos do Conselho, da Comissão e do Banco Central Europeu, que não sejam recomendações ou pareceres, e dos atos do Parlamento Europeu destinados a produzir efeitos jurídicos em relação a terceiros.

Compete, ainda, a ele conhecer dos recursos com fundamento em incompetência, violação de formalidades essenciais, violação do Tratado da União Europeia ou de qualquer norma jurídica relativa à sua aplicação, ou em desvio do poder, interpostos por um Estado membro, pelo Conselho ou pela Comissão. Tem competência, também, nas mesmas condições, para conhecer dos recursos interpostos pelo Parlamento Europeu, pelo Tribunal de Contas e pelo Banco Central Europeu com o objetivo de salvaguardar as respectivas prerrogativas.

Nesse diapasão, Diego Pereira Machado esclarece que (2012, p. 418):

Os seus acórdãos são vinculativos e devem ser cumpridos pelos Estados membros. Se verificado que um Estado não cumpriu qualquer das obrigações que lhe incumbem por força dos tratados, ele deve tomar as medidas necessárias à execução. Se a Comissão considerar que o Estado em causa não tomou as medidas tendentes à execução da decisão, pode submeter o caso novamente ao Tribunal, após ter dado ao Estado a possibilidade de apresentar as suas observações (uma espécie de defesa). Se o Tribunal declarar verificado que o ente em causa não deu cumprimento ao seu acórdão, pode condená-lo ao pagamento de uma quantia fixa ou progressiva correspondente a uma sanção pecuniária. 
As decisões do Tribunal de Justiça da União Europeia, são irrecorríveis e têm força executiva imediata nos territórios dos Estados membros, produzindo força obrigatória desde o dia em que foram proferidas.

\subsection{BANCO CENTRAL EUROPEU}

Este Banco foi criado em 30 de junho de 1998, mas somente começou a funcionar em 01 de janeiro de 1999, com sede em Frankfurt, na Alemanha.

É um órgão supranacional, com personalidade jurídica própria e com atribuições para a execução das políticas econômicas e monetárias da União, competindo-lhe gerir o euro (emitir as notas para circulação).

Essa instituição é governada por um Conselho, por uma Comissão Executiva e por um Conselho Geral, adotando, no exercício de suas atribuições, regulamentos, decisões e recomendações.

O Banco Central é o núcleo do Eurosistema e do Sistema Europeu de Bancos Centrais. O Eurosistema é constituído pelo Banco Central Europeu e pelos Bancos Centrais dos Países que adotam o euro. Já o Sistema Europeu de Bancos Centrais é constituído pelo Banco Central Europeu e pelos bancos centrais nacionais de todos os Estados membros da União Europeia, independentemente de terem adotado ou não o euro como moeda.

\subsection{TRIBUNAL DE CONTAS DA UNIÃO EUROPEIA}

O Tribunal de Contas da União Europeia é responsável pela legalidade do orçamento da União Europeia; fiscalização das contas e fiscalização do orçamento da União Europeia.

Ademais, é composto por um representante de cada Estado membro, sendo nomeados para um período de seis anos. A escolha é feita pelo Conselho, após consulta ao Parlamento Europeu.

O Tribunal foi criado pelo Tratado de Bruxelas em 22/07/1975 e é uma instituição que desempenha controle eficiente sobre a gestão financeira e orçamentária do bloco.

Convém frisar que a principal função do Tribunal de Contas da União Europeia é comprovar que o orçamento comunitário se executa corretamente, e dizer, que os gastos da União Europeia são legais e claros, assegurando uma sadia gestão financeira.

Para realizar suas atribuições, o Tribunal pode investigar a documentação de qualquer organização que administre receita ou execute gastos da União Europeia. 


\section{CONSIDERAÇÕES FINAIS}

O processo de unificação europeia teve início na década de cinquenta e, gradualmente, vem alcançando maior integração entre os Estados- membros.

O desenvolvimento da União Europeia não encontra comparações, visto que seu quadro institucional atual superou todos os demais projetos de aproximação entre os Estados, principalmente pelo seu caráter supranacional.

É uma entidade com personalidade jurídica única, baseada na supranacionalidade: as normas de Direito Comunitário estão acima das fontes nacionais. É, também, a principal representante do Direito Comunitário.

A União Europeia é amparada em quatro liberdades: a livre circulação de pessoas, de mercadorias, de serviço e de capital.

Os três tratados que deram início ao bloco, foram o da Comunidade Europeia do Carvão e do Aço (CECA). Os constitutivos da Comunidade Econômica Europeia (CEE) e a Comunidade Europeia da Energia Atômica (EUROTAM).

A União Europeia é composta por vários organismos, cada um deles tem sua função específica, os quais são: Parlamento Europeu; Conselho Europeu; Conselho; Comissão Europeia; Tribunal de Justiça da União Europeia; Banco Central Europeu e Tribunal de Contas da União Europeia.

Ademais, a União Europeia, como bloco “ forte” que é possui dois documentos importantes que são: o ACORDO SCHENGEN e a CARTA COMUNITÁRIA DOS DIREITOS FUNDAMENTAIS SOCIAIS DOS TRABALHADORES.

O ACORDO SCHENGEN, trata sobre a liberdade de circulação das pessoas em sentido amplo. A União Europeia autoriza a entrar em qualquer país do acordo Schengen. Uma das discussões foi a própria ideia da nacionalidade. Em alguns Países, e aqui no Brasil, é possível que o estrangeiro se naturalize nacional do País quando casa com nacional. $\mathrm{O}$ acordo Schengen não admite que europeias, ao casarem com estrangeiros, transmitam de forma automática a sua nacionalidade. Isso foi acordado para conter algumas situações relacionadas ao próprio Oriente Médio, Ásia, África e América. Isso gerou muita controvérsia, mas está consolidado desta forma por decisão do Tribunal de Justiça Europeu.

Então, a partir do Acordo de Schengen, começou-se a desenvolver a ideia de uma pessoa morar em um País, ser nacional de um segundo País e trabalhar em um terceiro País. 


\section{A CARTA COMUNITÁRIA DOS DIREITOS FUNDAMENTAIS SOCIAIS DOS}

TRABALHADORES, trata de questões sobre livre circulação; emprego; melhora das condições de vida e de trabalho; proteção social; liberdade de associação e negociação coletiva; formação profissional; igualdade de tratamento ente homens e mulheres; informação e participação dos trabalhadores; entre outros.

Em suma, quando se fala em Direito Comunitário, o melhor exemplo é a União Europeia. Tanto é verdade que a União Europeia tem figurado entre as mais noticiadas na imprensa, por ocasião do recente acordo firmado entre Mercosul e União Europeia.

Nesse diapasão, é inegável o papel que as ações afirmativas exercem no contexto da globalização, onde ainda existe o individualismo e o consumismo. São marcas fortes que não deveriam existir, pois hoje o mundo é um só e deve haver aceitação de todos seres humanos como merecedores de respeito e dignidade, bem como inclusão social. O mundo globalizado não pode ser motivo de segregação; nas relações internacionais (blocos econômicos potentes), não devem prevalecer as desigualdades, as intolerâncias e sim, o culto à liberdade e igualdade entre as nações e seus indivíduos.

\section{REFERÊNCIAS}

KRIEGER, César Amorin. Direito Internacional Humanitário. Curitiba: Juruá.2006.

MACHADO, Diego Pereira. Direito internacional e comunitário para concursos de magistratura do trabalho. 2 ed. rev. atual. e ampl. São Paulo: EDIPRO, 2012.

MAZUOLLI, Valerio de Oliveira. Curso de direito internacional público. 2 ed. rev. atual. e ampl. São Paulo: Editora Revista dos Tribunais, 2007.

SILVA, Carla Ribeiro Volpini; ROMANO, Taisse June Barcelos Maciel. A PROTEÇÃo INTERNACIONAL DOS REFUGIADOS AMBIENTAIS FUNDAMENTADA NOS MECANISMOS DE PROTEÇÃO DO DIREITO INTERNACIONAL DOS REFUGIADOS. Revista Juridica, [S.1.], v. 3, n. 48, p. 428 - 457, set. 2017. ISSN 2316-753X. Disponível em: <http://revista.unicuritiba.edu.br/index.php/RevJur/article/view/2188/1368>. Acesso em: 21 abr. 2020. doi:http://dx.doi.org/10.21902/revistajur.2316-753X.v3i48.2188.

STELZER, Joana. União Europeia e Supranacionalidade: Desafio ou Realidade? Curitiba: Juruá, 2000.

STELZER, Joana; SOUZA, Silvano Denega; OLIVEIRA, Adrielle Betina I.. CADEIAS GLOBAIS DE VALOR (CGV): A FRAGMENTAÇÃO DO PROCESSO PRODUTIVO CONFORME A ORGANIZAÇÃO MUNDIAL DO COMÉRCIO. Revista Juridica, [S.1.], 
v. 4, n. 57, p. 399 - 421, fev. 2020. ISSN 2316-753X. Disponível em: <http://revista.unicuritiba.edu.br/index.php/RevJur/article/view/3779/371372137>. Acesso em: 21 abr. 2020. doi:http://dx.doi.org/10.21902/revistajur.2316-753X.v4i57.3779. 